\title{
Study of Right Ventricular Pacing Threshold at National Teaching Hospital of Cotonou in Benin
}

\author{
Arnaud Sonou ${ }^{1, *}$, Tchaa Tchérou ${ }^{2}$, Philippe Mahouna Adjagba ${ }^{3}$, Murielle Hounkponou ${ }^{3}$, \\ Léopold Codjo $^{4}$, Salimatou Assani ${ }^{3}$, Wilfried Gandji ${ }^{3}$, Yessoufou Tchabi ${ }^{3}$, Martin Houénassi ${ }^{3}$ \\ ${ }^{1}$ Department of Cardiology, Departmental Teaching Hospital of Ouémé-Plateau, University of Abomey-Calavi, Porto-Novo, Benin \\ ${ }^{2}$ Department of Cardiology, University Teaching Hospital of “Campus”, Lomé, Togo \\ ${ }^{3}$ Department of Cardiology, Teaching Hospital of Cotonou, University of Abomey-Calavi, Cotonou, Benin \\ ${ }^{4}$ Department of Cardiology, Departmental Teaching Hospital of Borgou-Alibori, University of Parakou, Parakou, Benin
}

Email address:

arnsonou@gmail.com(A. Sonou),tcheroutchaa@gmail.com(T. Tchérou),dotoup@yahoo.fr(P.M. Adjagba), kayivi2003@yahoo.fr(M. Hounkponou), leostelles@yahoo.fr(L.Codjo), reinesali@yahoo.fr(S.Assani), elowilly@yahoo.fr(W.Gandji), youftchabi@yahoo.fr(Y.Tchabi),houenassi_m@yahoo.fr(M. Houénassi)

${ }^{*}$ Corresponding author

\section{To cite this article:}

Arnaud Sonou, Tchaa Tchérou, Philippe Mahouna Adjagba, Murielle Hounkponou, Léopold Codjo, Salimatou Assani, Wilfried Gandji, Yessoufou Tchabi, Martin Houénassi. Study of Right Ventricular Pacing Threshold at National Teaching Hospital of Cotonou in Benin. American Journal of Internal Medicine. Vol. 6, No. 3, 2018, pp. 47-51. doi: 10.11648/j.ajim.20180603.12

Received: May 2, 2018; Accepted: May 21, 2018; Published: June 14, 2018

\begin{abstract}
The main purpose was to study the right ventricular pacing threshold of patients who benefit from cardiac pacemaker's implantation at the National Teaching Hospital of Cotonou in Benin. This was a retrospective study from January 2007 to September 2013. The right ventricular pacing threshold measured during successive checks has been studied. A threshold greater than 1 volt was considered high. The conventional causes of threshold's rising were sought. 35 files were examined. The average threshold of our patients amounted to $1.24 \pm 1.17$ volts at the first control and remained high until the end of follow-up. The prevalence of threshold elevation was $17 \%(6 / 35)$. The causes of threshold elevation were: late displacement of the lead ( 1 case), faulty lead ( 1 case), and suspected lead's micro dislodgment ( 1 case). There was no formal etiology found for 3 cases. Half of threshold elevation cases involved a problem of pacing lead. Similar findings have been reported by previous studies. This study has confirmed that threshold elevation mainly involved pacemaker lead. The premature need to change the pacemaker caused by this elevation has considerable consequences in a Beninese local context marked the lack of governmental facilities.
\end{abstract}

Keywords: Threshold, Cardiac Pacing, Benin

\section{Introduction}

The aging population has led to an increased number of pacemaker implantations around the world. In the United States of America, approximately 2.25 million pacemakers have been implanted in 12 years, and this number increases annually by approximately $3 \%$ [1]. In sub-saharian Africa, 730 pacemakers have been implanted in 3 years in 8 countries [2]. Benin, which also has a cardiac pacing unit, is confronted with concerns related to monitoring, particularly the desire to have the best possible longevity of the implanted pacemaker. In fact, patients pay themselves with difficulty the material of cardiac stimulation, which makes stressing the prospect of pacemaker change. A good longevity of the pacemaker involves stabilization at a low level of the stimulation threshold, defined by the lowest energy that can cause a contraction of the heart muscle. The assessment of this stimulation threshold represents an important phase in the follow-up of the patient with pacemaker. Since the start of cardiac pacing activity in Benin, cases of threshold elevation were identified. These cases have been reported in this work. Precisely, the evolution of the stimulation threshold has been appreciated, the rate of the threshold elevation has been highlighted and the causes of this 
elevation have been investigated.

\section{Patients and Method}

A retrospective and descriptive study from January 2007 to September 2014 has been realized. The records of patients who have benefited from a first pacemaker implantation at the Cardiologic Clinic of the National Teaching Hospital of Cotonou in Benin, and who were followed for at least 3 months were used.

The parameters studied were the right ventricular pacing threshold measured during implantation and after the implantation in the periods of 3-12 months, 12-24 months, 23 years and finally from 4 years. A threshold greater than 1 volt was considered high. The conventional causes of threshold elevation were sought. Cardiac causes (myocarditis, myocardial infarction, myocardial perforation), metabolic and inflammatory causes were searched during interrogation (chest pain, dyspnea), physical examination (long-standing fever, heart failure) and paraclinical examinations (C-Reactive Protein, kaliemia, fasting glucose, serum creatinine, cardiac enzymes, echocardiographic signs of myocardial infarction or of tamponade). Iatrogenic causes like amiodarone, verapamil, propanolol, quinidine and antiarythmics drugs of class Ic were checked. Leads abnormalities (displacement, fracture or insulator breakage) were searched using chest X-ray, lead impedance, detection and stimulation measures. Indeed, a lead displacement associates a loss of stimulation and detection, and a rise of stimulation impedance. This displacement can be visible radiologically or not (micro-displacement). An insulator breakage leads to a decrease of lead impedance while a lead fracture leads to a rise of this impedance.

The other parameters studied were the stimulation mode, active ou passive fixation lead, heart diseases and other diseases associated with the indication of definitive cardiac stimulation (diabetes, hyperkaliemia, left ventricular systolic dysfunction, pulmonar arterial hypertension, right ventricular systolic dysfunction, renal failure).

\section{Results}

\subsection{General Characteristics}

From January 2007 to the end of 2013, 98 pacemaker implantations were performed at the Cardiologic Clinic of National Teaching Hospital of Cotonou. Among the 98 cases, there were 76 cases of first implantation and 22 cases of pacemaker change. Of the 76 cases of first implantation, 47 patients were regularly followed in this Unit; 35 patients of them had a complete file, constituting the sample of the study. All patients were followed for a period of at least 3 months.

The mean age of the sample was $66 \pm 10.8$ years with a sex ratio $\mathrm{M} / \mathrm{F}$ of 1.05 .
A dual chamber pacemaker was implanted in 22 patients and a single chamber pacemaker in 13 patients. The lead fixation mechanism was passive in $91.43 \%$ of cases compared to $8.57 \%$ for active fixation. Diabetes, left ventricular systolic dysfunction and high blood pressure were the heart diseases most frequently encountered in the sample (Table 1).

Table 1. Distribution of patients according to heart disease, associated diseases and antiarythmic in use.

\begin{tabular}{lll}
\hline & Size, $\mathbf{N}=\mathbf{3 5}$ & $\mathbf{\%}$ \\
\hline Diabets & 5 & 14.28 \\
Hyperkaliemia & 0 & 0 \\
Renal failure & 2 & 5.71 \\
Systemic disease & 0 & 0 \\
Myocardial infarction & 0 & 0 \\
RLVEF & 3 & 8.57 \\
PAH & 3 & 8.57 \\
RRVEF & 0 & 0 \\
Bêta-blocker & 1 & 2.85 \\
Antiarythmic classe Ic & 0 & 0 \\
\hline
\end{tabular}

$\mathrm{RLVEF}=$ reduced left ventricular ejection fraction, $\mathrm{PAH}=$ pulmonar arterial hypertension, $\mathrm{MI}=$ myocardial infarction, $\mathrm{RRVEF}=$ reduced right ventricular ejection fraction.

\subsection{Study of Thresholds}

\subsubsection{Level of Thresholds}

The mean threshold of patients, which was normal during the implantation $(0.52 \pm 0.49$ volts $)$, has risen at the first control and remained high during subsequent controls (Table 2).

Table 2. Evolution of the mean right ventricular pacing threshold according to follow-up periods.

\begin{tabular}{ll}
\hline Follow-up periods & Stimulation threshold \\
\hline During implantation & $0.52 \pm 0.49$ volts \\
First control (3-6 months) & $1.24 \pm 1.17$ volts \\
Second control (12-18 months) & $1.01 \pm 0.97$ volts \\
Third control (2-3 years) & $1.14 \pm 1.06$ volts \\
Fourth control ( $\geq 4$ years) & $1.25 \pm 1.24$ volts \\
\hline
\end{tabular}

Table 3 shows the proportion of patients with a high right ventricular pacing threshold during implantation and followup. 6 cases of threshold elevation were found on the 35 files, giving a percentage of $17.14 \%$.

Table 3. Distribution of patients according to right ventricular pacing thresholds $\leq 1$ volt or $>1$ volt during the follow-up.

\begin{tabular}{lll}
\hline Follow-up periods & Threshold $\leq 1$ volt & Threshold $>$ 1 volt \\
\hline During implantation & $33 / 35$ & $2 / 35$ \\
First control (3-6 months) & $30 / 35$ & $5 / 35$ \\
Second control (12-18 months) & $27 / 32$ & $5 / 32$ \\
Third control (2-3 years) & $20 / 26$ & $6 / 26$ \\
Fourth control ( $\geq 4$ years) & $12 / 17$ & $5 / 17$ \\
\hline
\end{tabular}

The rise of threshold occured quite earlier in most of cases $(5$ on 6), only one case was recorded beyond 2 years (Figure 1). 


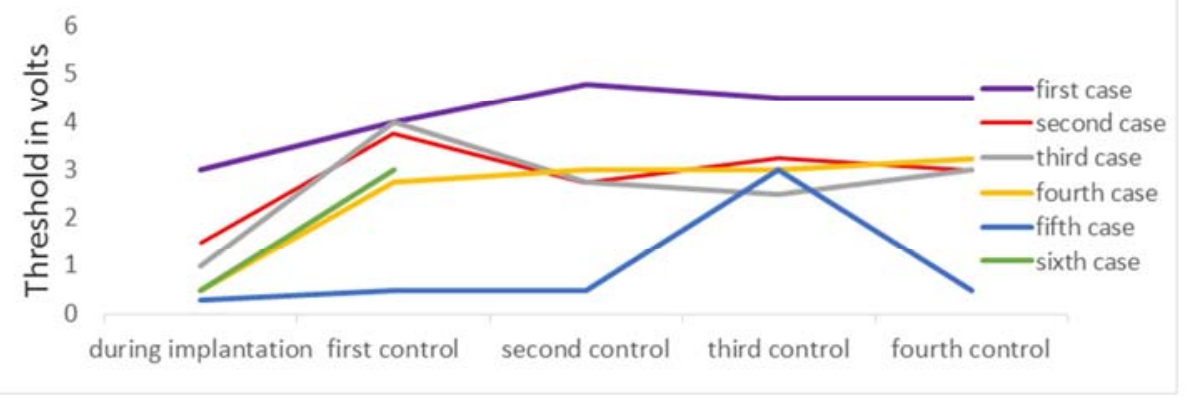

Figure 1. Right ventricular pacing threshold evolution in patients whose threshold has risen during the follow-up.

\subsubsection{Causes of Thresholds Elevation}

The causes of threshold elevation were distributed as follows:

1. one late lead displacement which were repositioned

2. one case of suspected faulty lead because the threshold raised to 3 volts during the implantation and remained high reaching 5 volts until the complete unloading of the pacemaker battery with a normal lead impedance; the implantation of a new lead resulted in a good threshold of 0.6 volts

3. one case of lead micro-displacement (Figure 2)

4. 3 cases without known etiology.

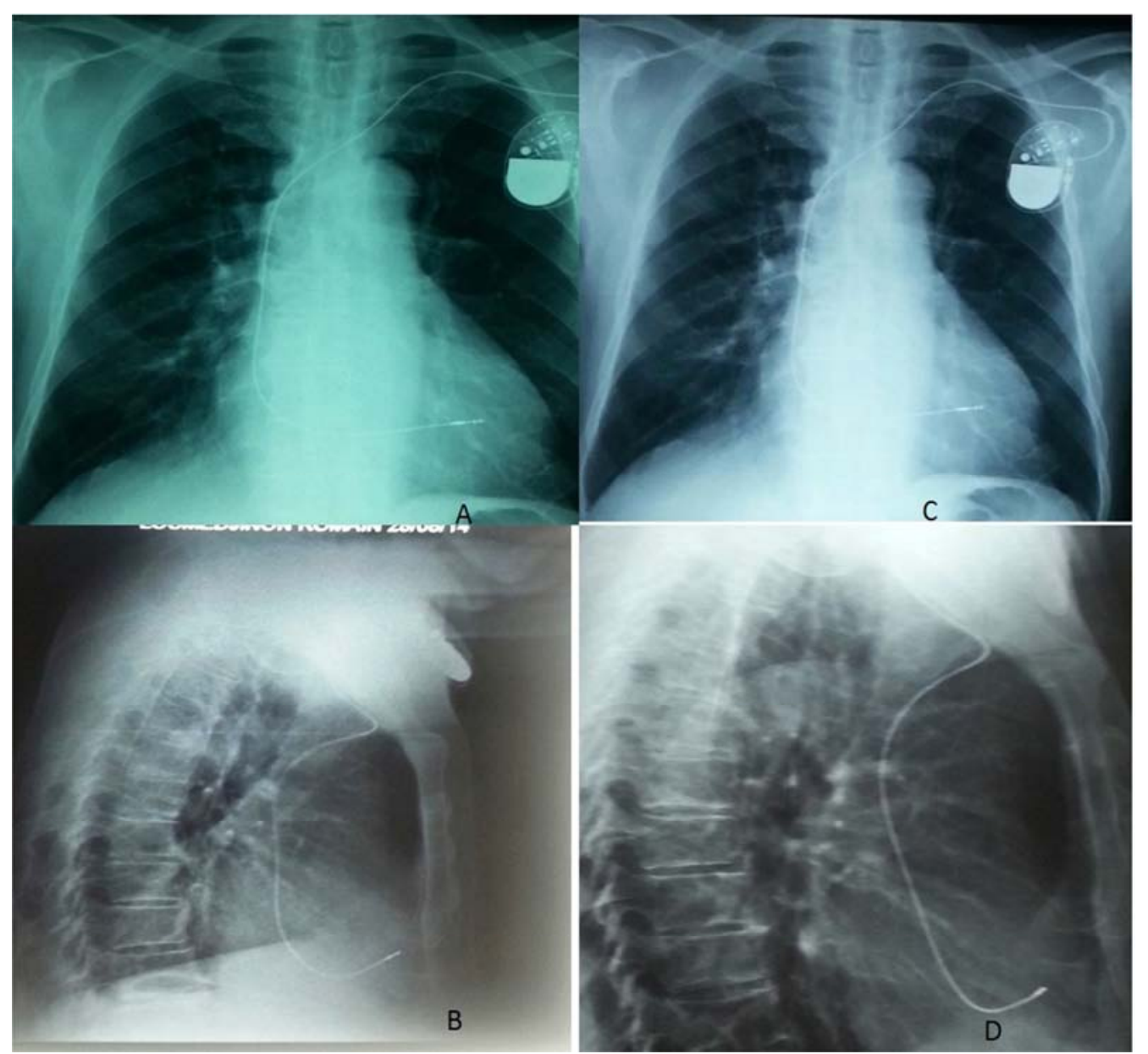

Figure 2. Lead micro-displacement suspicion: chest X-rays face incidence (picture A) and profile incidence (picture B). Immediately after pacemaker implantation, control chest $X$-rays (pictures $C$ and $D$ ) after pacing threshold raising.

Table 4 shows the distribution of threshold elevation cases according to fixation mechanism, type of pacemaker (single chamber or dual chamber) and associated heart disease. No relationship was found between these parameters and the raising of the threshold. 
Table 4. Distribution of cases of right ventricular pacing threshold elevation according to lead fixation mechanism, pacemaker type and associated heart disease.

\begin{tabular}{ll}
\hline & Size of cases/sample size \\
\hline Mechanism of lead fixation & \\
Active fixation & $2 / 3$ \\
Passive fixation & $4 / 32$ \\
Pacemaker type & \\
Dual chamber & $4 / 22$ \\
Single chamber & $2 / 13$ \\
Associated heart disease & \\
MI & $0 / 0$ \\
RLVEF & $0 / 3$ \\
PAH & $1 / 3$ \\
RRVEF & $0 / 0$ \\
\hline
\end{tabular}

$\mathrm{LV}=$ left ventricle; $\mathrm{RV}=$ right ventricle; $\mathrm{PAH}=$ pulmonar arterial hypertension; $\mathrm{MI}=$ myocardial infarction, $\mathrm{RLVEF}=$ reduced left ventricular ejection fraction; RRVEF=reduced right ventricular ejection fraction.

Table 5 shows the distribution of threshold elevation cases according to associated diseases et antiarythmic drugs in use. No relationship was found between these parameters and the raising of the threshold.

Table 5. Distribution of cases of right ventricular pacing threshold elevation according to associated diseases and antiarythmic in use.

\begin{tabular}{ll}
\hline & Size of cases/sample size \\
\hline Diabetes & $0 / 5$ \\
Hyperkaliemia & $0 / 0$ \\
Renal failure & $0 / 2$ \\
Systemic disease & $0 / 0$ \\
Bêta-blocker & $0 / 1$ \\
Antiarythmic classe Ic & $0 / 0$ \\
\hline
\end{tabular}

\section{Discussion}

Cardiac stimulation is booming in sub-saharan Africa and Benin is not apart from this mutation. In exemple, pacemaker implantation rate was 98 in 6 years in Benin, 369 in 7 years in Ivory Coast and 338 in 8 years in Senegal [3]. The importance of the activity depends on the availability of cardiologists to perform implantation, the availability of cardiologists and physicians to provide indications of cardiac stimulation and finally on the policy implemented by each state to promote the financial accessibility of patients [4].

\subsection{Threshold Elevation and its Consequences}

Six cases of stimulation threshold rise $(17.4 \%)$ were found whose one case of late lead displacement, one case of faulty lead, one case of lead micro-displacement et 3 cases without known cause. BOURAOUI [5] and SDIRI [6] in Tunisia reported respectively $2.99 \%$ and $2.12 \%$ of unexplained right ventricular pacing threshold elevation in samples of respectively 234 and 188 patients. The FOLLOWPACE study which followed between january 2003 and november 2007, 1517 patients from 23 dutch hospitals, has recorded $0.79 \%$ of threshold rise 2 mois after implantation and $1.71 \%$ at the end of the follow-up [7]. The proportion of $17 \%$ recorded in this article can be explained by the small size of the sample. A stimulation threshold rise results in faster unloading of the battery and then a premature need to change it. In Benin, patients cannot benefit from a governemental facilities. The main consequence is that the patent who need cardiac stimulation have to pay himself for a dual chamber pacemaker, 2300 euros which represent 38 fold the interprofessional guaranteed minimum wage of Benin. In this context, the need to change pacemaker in a patient who is absolutely dependent on the cardiac stimulation pacemaker is a very stressful situation.

\subsection{The causes of Threshold Elevation}

According to the results reported in this article, threshold elevation has occurred with all types of leads, and previous publications point in the same direction $[8,9]$.

Lead displacement is a complication frequently reported in cardiac stimulation and responsible of a stimulation threshold increase or even a loss of capture. AGGARWAL in UnitedKingdom and ADEOYE in Nigeria respectively reported $2.9 \%$ and $4 \%$ of lead displacement cases $[10,11]$.

Among the 6 cases of threshold elevation, complications related to stimulation lead were responsible of 3 cases (displacement, micro-displacement, faulty lead). In the samples of BOURAOUI and SDIRI, high stimulation threshold was also largely caused by a lead problem (displacement, fracture) [5, 6]. The other causes of threshold elevation (hyperkaliemia, systemic diseases, myocardial infarction) are less frequent and often published in the form of isolated cases [12, 13].

The leadless pacemakers are a solution to avoid complications due to pacemaker lead. These devices are directly implantable in the right ventricle and have in addition the advantage of solving the aesthetic problem sometimes posed by the scar of a conventional pacemaker. However, the acute and chronic complications of this therapy as well as the feasibility of explant years after implantation are unresolved questions [14].

The results of this article reported also 3 cases without known etiology. Some authors have proposed, as another option to the lead repositioning, the use of corticosteroids (prednisolone 60mg per day). This treatment may be continued on one month if a significative decrease of the threshold was obtained from the 5th day. On the other hand, this treatment should be discontinued $[15,16]$. There is no official recommendation of this practice but this option, if chosen, should take into account the comorbidities of the patient.

\section{Conclusion}

The study of the ventricular pacing threshold of patients implanted and monitored at the Cardiologic Clinic of the National Teaching Hospital of Cotonou found 17.14\% of stimulation threshold elevation. The local context in Benin state characterized by a difficult financial accessibility to this therapy, premature need to changes the devices could generate very stressful situations. The etiologies of this threshold elevation are mainly due complications involving the lead. The leadless pacemaker is an interesting solution. 


\section{References}

[1] Maisel WH. Pacemaker and ICD generator reliability: metaanalysis of device registries. JAMA 2006; 295: 1929-34.

[2] Kane A. et coll. Problematique de la stimulation cardiaque definitive en Afrique subsaharienne: étude multicentrique STIMAFRIQUE. Cardiologie tropicale 2016; 23 (143): 20.

[3] Adoubi KA, Kendja KF, Tano M, Koffi F, Ndjessan JJ, Meneas $\mathrm{C}$ et coll. Activities report of Abidjan Cardiology Institute pacing Unit from 2006 to 2012. Cardiovascular Journal of Africa 2013; 24 (5).

[4] Jouven X. La stimulation cardiaque en Afrique de l'Ouest. Annales de Cardiologie et d'Angéiologie 2003; 52 (4): 204.

[5] Bouraoui H, Trimech B, Chouchene S, Mahdhaoui A, Hajri $\mathrm{SE}$, Jeridi $\mathrm{G}$ et coll. La stimulation cardiaque permanente: à propos de 234 patients. La Tunisie Medicale 2011; 89 (07): 604-609.

[6] Sdiri W, Marouf A, Mbarek D, Ben Slima H, Mokaddem A, Ben Ameur $\mathrm{Y}$ et coll. Résultats de la stimulation cardiaque définitive: à propos de 188 malades. La tunisie Médicale 2013; 91 (06): 396-401.

[7] Udo EO, Van Hemel NM, Peter N, Zuithoff A, Nijboer H, Taks W and al. Incidence and predictors of shortand long-term complications in pacemaker therapy: The FollowPace study. Heart Rhythm. 2012; 9(5):728-35.

[8] Hai-Bo Y, Yan-Chun L, Guo-Qing X. The Comparison Between the Active-Fixation Leads and Passive-Fixation Leads in Right Ventricular Apical Pacing. Heart 2013; 99:A8A9. doi:10.1136/heartjnl-2013-303992.027.

[9] Liu L, Tang J. A long-term, prospective, cohort study on the performance of right ventricular pacing leads: comparison of active-fixation with passive-fixation leads. Scientific Reports 2015, 5: 7662. doi: 10.1038/srep07662.

[10] Aggarwal RK, Connelly DT, Ray SG, Ball J, Charles RG. Early complications of permanent pacemaker implantation: no difference between dual and single chamber systems. $\mathrm{Br}$ HeartJ1 1995; 73:571-575.

[11] Peter O. Adeoye, Kelechi E. Okonta, Mudasiru A. Salami, Victor O. Adegboye. Experience with permanent pacemaker insertion at the University College Hospital, Ibadan, Nigeria. Nigerian Journal of Cardiology 2013; 10 (1): 3-5.

[12] Barold S, Falkoff M, Ling S, Robert A. HyperkalemiaInduced Failure of Atrial Capture during Dual-Chamber Cardiac Pacing. J Am Coll Cardiol 1987; 10:467-9.

[13] Takasugi N, Kubota T, Kawamura I, Takasugi M, Kanamori $H$. Sudden reversible pacemaker failure in a patient with cardiac sarcoidosis: an unfortunate case of ventricular septal pacing. Doi: 10.1093/eupace 2012/eur435.

[14] Sperzel J, Burri H, Gras D, Tjong FVY, Knops ER, Hindricks $\mathrm{G}$ and al. State of the art of leadless pacing. Europace 2015; 17:1508-1513.

[15] Paul A. Levine. Management of the Patient with an Acute Massive Rise in the Capture Threshold. Indian Pacing and Electrophysiology Journal 2001, 1(1): 35-37.

[16] Nagatomo Y, Ogawa T, Kumagae H, Koiwaya Y, Tanaka K. Pacing failure due to markedly increased stimulation threshold two years after implantation: successful management with oral prednisolone. PACE 1989; 12: 1034-1037. 